\title{
ETNOGRAFIA DA MÚSICA COM ABORDAGEM ANTROPOLÓGICA: RITOS RELIGIOSOS NO CENTRO DE UMBANDA CASA DE CARIDADE MÃE MARIA
}

\section{ETHNOGRAPHY OF MUSIC UITH ANTHROPOLOGICAL APPROACH: RELIGIOUS CEREMONIES AT CENTRO DE UMBANDA CASA DE CARIDADE MÃE MARIA}

\author{
Bianca Viana Monteiro da Silva \\ Universidade de São Paulo \\ bianca.viana.silva@usp.br \\ Marcos Câmara de Castro \\ Universidade de São Paulo \\ mcamara@usp.br
}

\section{Resumo}

Este artigo tem a finalidade de descrever sobre um trabalho etnográfico realizado no Centro de Umbanda Casa de Caridade Mãe Maria (CCMM) com abordagem antropológica. A pesquisa foi realizada na cidade de Ribeirão Preto-SP. É uma pesquisa qualitativa com o propósito de relatar uma prática de trabalho de campo, na qual a música foi inserida em um contexto cultural. Foi um trabalho de observação, na qual foi descrito o que vimos. Foi estabelecida a relação entre: visão, olhar, memória, imaginário, descrição do ritual e das regras do grupo.

Palavras-chave: Umbanda; Etnomusicologia; Pesquisa em campo.

\section{Abstract}

The purpose of this article is to describe in an ethnographic work carried out in the Center of Umbanda Casa de Caridade Mãe Maria (CCMM). The research was carried out in Ribeirão Preto-SP. It is a qualitative research performed with the purpose of reporting a field work practice, in which music was inserted in a cultural context. It was an observation work, in which we described what we saw. The relation 
between: vision, look, memory, imaginary, description of the ritual and the rules of the group was established.

Keywords: Umbanda; Ethnomusicology; Field research.

\section{Caracterização do trabalho}

Esta pesquisa tem natureza qualitativa. As investigações qualitativas "recolhem normalmente os dados em função de um contacto aprofundado com os indivíduos, nos seus contextos ecológicos naturais" (BOCDAN; BIKLEN, 1994, p.16). Uma das táticas da investigação qualitativa são observação e entrevista. "O investigador introduz-se no mundo das pessoas que pretende estudar, tenta conhecê-las, dar-se a conhecer e ganhar a sua confiança (...)" (BOCDAN; BIKLEN, 1994, p. 16). $\bigcirc$ artigo apresentado é um trabalho etnográfico desenvolvido em formato de "caderno de campo", na qual nós registramos e descrevemos a cultura em que estava sendo assistida: a atividade religiosa desenvolvida na Casa de Caridade Mãe Maria (CCMM). Por ser um trabalho etnográfico ligado à música, denominamos que seja do campo da etnomusicologia ou etnografia da música. De acordo com - dicionário de português onlinel, a definição de etnomusicologia é: "também conhecida como antropologia da música, ou mais propriamente etnografia da música, é a ciência que objetiva o estudo da música em seu contexto cultural ou o estudo da música como cultura". No mesmo sentido, Aurélio Buarque de Holanda Ferreira a descreve como: "estudo dos sistemas musicais dos diversos povos, em seus aspectos formais (os sons e as maneiras de combiná-los) ou socioculturais (usos e comportamentos relativos à música, o papel desta, etc.)" (FERREIRA, 2004, p. 843). Tais definições corroboram com este trabalho o qual proporcionou a vivência de uma tradição religiosa além do acesso aos meios de transcrição musicais e rituais. Determinamos que a abordagem etnográfica aqui usada seja precisamente antropológica. Para Pinto (200 I), esta abordagem:

Caracteriza-se pela postura do pesquisador, que vê a música inserida no seu contexto cultural. Dá-se importância ao todo, isto é, à "música na cultura" e à "música enquanto

I Disponivel em: <http://dicionarioportugues.org/pt/etnomusicologia> 
cultura" (Merriam, 1964; 1977). O registro do áudio e de imagens ultrapassa o puramente musical (PINTO, 2001, p. 251).

Destacamos, então, a diferença entre uma abordagem antropológica de uma abordagem musicológica. Nesta, o "fenômeno musical enquanto texto e estrutura estão em primeiro plano" (PINTO, 2001 , p. 5 1), enquanto na abordagem antropológica (fundamentação da nossa pesquisa) a música é observada em seu contexto cultural.

Centro de Umbanda CCMM é localizado na Rua Júlio Ribeiro, 260, bairro Vila Virgínia - Ribeirão Preto-SP. Foi fundado em 13 de maio de 1987 pela Madrinha Maria Aparecida das Graças Cobbo Gaspar. Pela perda da Madrinha em maio do ano de 2016, o Centro foi, desde então, dirigido pelo seu marido, Ademir Gaspar. Para desenvolvermos este trabalho, apresentamos a ideia da pesquisa ao Ademir, o qual gentilmente permitiu a realização. Além da autorização da filmagem e fotos, ele colaborou com relatos sobre a religião e sobre a história do Centro.

As atividades do Centro seguiram as linhas das entidades de: Preto Velho, Caboclo, Baianos, Esquerda e Cosme e Damião. Acompanhamos semanalmente os encontros no Centro durante um semestre do ano de 2016, nas segundas-feiras e sextas-feiras, das 19 h30 às $21 \mathrm{~h}$. Tivemos a permissão de filmar e fotografar os processos dos rituais dos trabalhos/ giras. A música era como uma preparação para começar e encerrar os trabalhos, tendo, durante o processo, a incorporação das entidades.

\section{A origem da umbanda}

Em 1763, no Rio de Janeiro, o Brasil passou a receber africanos originários da Angola e do Congo. Os africanos trouxeram para o Brasil a sua cultura religiosa - Candomblé. $\bigcirc$ Candomblé difundiu-se pela cidade com o nome genérico de Macumba, mediante as sobrevivências bantas, indígenas e o espiritismo. Posteriormente, Macumba passou a receber a designação de Umbanda. Sobre isso, Edson Carneiro ( 1991 ), diz: 
As confrarias, chamadas a princípio de macumbas, compreendiam a linguagem mágica dos tambores e a possessão da divindade de acordo com o modelo original - e por isso se viram expulsas do perímetro urbano carioca; as sucessoras, ou aquelas que se adaptaram às novas exigências policiais, passaram a chamar-se umbanda (CARNEIRO, 1991, p. 42).

Com a vinda dos africanos no Brasil Colônia - para servirem de trabalho escravo, fundiu-se o Candomblé. Este passou por outras influências e modificações, o que originou a Umbanda. As crenças, músicas e práticas religiosas contribuíram para a formação desta religião afro-brasileira. Pode-se dizer que a Umbanda foi identificada como a religião brasileira por excelência, por ter sido formada no Brasil.

Prandi (2004) afirma que a Umbanda, além das raízes do Candomblé, tem influências do espiritismo kardecista e do catolicismo. Sobre essa questão, Ortiz considera a Umbanda como: "uma religião endógena, que situa na encruzilhada de três raças que contribuíram para a formação do povo brasileiro" (ORTIZ apud ROTTA, 2010, p. 31 ). Rotta (2010, p. 31 ) destaca que tal sincretismo religioso possui raizes indígena, africana e europeia, o que proporciona a especificidade de uma religião genuinamente brasileira dada à fusão destes cultos.

\section{As entidades presentes nos trabalhos do Centro de Caridade Mãe Maria}

Os umbandistas cultuam os ancestrais que são chamados de guias espirituais (as entidades). São espíritos que já viveram na Terra, e no momento da gira retornam por meio do corpo dos médiuns esse manifesto é chamado de psicofonia (comunicação de espíritos por meio da voz do médium), ou, no sentido mais vulgar, incorporação. Essa manifestação é feita apenas por pessoas que tem essa habilidade - são chamadas de médiuns de psicofonia. Quando esses médiuns incorporam alguma entidade, há as pessoas do Centro que têm a função de auxiliá-los. Elas são designadas com o nome de Cambones. A função dos Cambones é de: ajudar a entidade e o médium, servir a entidade, colaborar com o trabalho e com a vibração do ambiente, 
ajudar (se necessário) a pessoa que é consultada a entender o que a entidade quis dizer e manter o sigilo do que for dito.

As entidades que a Casa de Caridade Mãe Maria recebe são: preto velho, caboclo, baiano, esquerda, crianças e ciganos. Como foi dito, a Umbanda é de origem brasileira, e Prandi (2005) afirma, também, que ela é caracterizada pela cultura brasileira: o caboclo seria a representação do índio, o preto velho seria o escravo sábio e o baiano seria o "valente nordestino" (ROTTA, 2010, p. 22).

Cada tipo um estilo de vida, cada personagem um modelo de conduta. São exemplos de um vasto repertório de tipos populares brasileiros, emblemas de nossa origem plural, máscaras de nossa identidade mestiça. As entidades sobrenaturais da umbanda não são deuses distantes e inaceitáveis, mas sim tipos populares como a gente, espíritos do homem comum numa variedade que expressa a diversidade cultural do próprio país (PRANDI apud ROTTA, 2010, p. 32).

Os trabalhos realizados neste Centro são nas segundas-feiras e nas sextas-feiras, e cada dia é dedicado à uma entidade (todas as segundas são recebidos os pretos velhos, a esquerda é recebida na última sexta do mês, e nas outras sextas são trabalhos alternados entre baianos e caboclos). Acompanhamos todos, exceto ciganos, por não ter a permissão de filmá-los (porém, este não ocorre com frequência - é realizado apenas uma vez por ano). $\bigcirc$ trabalho de crianças acontece apenas uma vez ao ano, na semana do dia de Cosme e Damião. Cada entidade tem uma vestimenta e ritos específicos que os diferem. Os ritos englobam crenças, músicas e práticas religiosas. Sobre as manifestações das entidades, Borges e Chada afirmam:

Há (...) a crença em um Ser Superior, embora a Ele não se façam rituais. Em seu lugar são cultuadas, através da música, várias divindades com características específicas, que servem de elos entre Deus e os homens. A manifestação das divindades nos iniciados se dá através dos rituais, propiciando a relação entre o mundo real e o sobrenatural. (...) chega-se à Deus pela alegria. Acredita-se que não é necessário o sofrimento para a purificação, mas, se Deus é 
a essência e amor, essa essência é alegre, assim como o real é reconhecido na forma da alegria e por isso busca-se fazer tudo cantando, com alegria e amor (BORGES; CHADA, 2008, p. 437).

\section{A atribuição da música presente nos ritos da Umbanda}

- trabalho de etnografia da música com abordagem antropológica propõe o estudo da música em seu contexto cultural, ou da música como cultura.

Falando-se de antropologia do som, ou sonora, dois elementos surgem à primeira vista: o som enquanto fenômeno físico e, simultaneamente, inserido em concepções culturais e, do outro lado, a música propriamente dita, isto é o som "culturalmente organizado" pelo homem (...). Os dois parâmetros, a acústica e a cultura, ou seja, o som e as sonoridades, respectivamente, estão presentes na pesquisa etnomusicológica do século XX. (QUEIROZ apud PINTO, p. $53,2017)$.

Na Umbanda, a música representa um fator de orientação e expressa os diferentes caracteres espirituais (PINTO, 2001, p. 255). Seu rito está atrelado também a outras manifestações: "vestuário, linguagem, simbologia pictórica e corporal, elementos construtivos, hábitos, padrões de comportamento, símbolos religiosos e pensamento, etc." (QUEIROZ, p. 53, 2017). Dessa forma, vemos que há uma cultura sendo manifestada por meio da música. Ademais, a música está intrinsecamente ligada ao movimento/dança e à letra: "a soma da música, da dança e do texto é o estímulo do transe $e^{2}$ que de fato é o comportamento esperado durante as cerimônias" (LUNELLI, 2015, p. 6).

No momento da música o corpo se movimenta em resposta aos pontos que estão sendo cantados, de acordo com a entidade em questão. No trabalho que foi desenvolvido, por exemplo, reparamos que no momento da gira dos baianos, eles se movimentam de forma mais alegre e são mais dançantes, ao ponto que os pretos velhos são mais

2 Consideramos transe como o momento da incorporação pelos médiuns de psicofonia. 
contidos. Isso ocorre de acordo com a origem de cada um quando encarnado. Vale ressaltar, que eles foram espíritos que já viveram na Terra, e no momento da gira retomam por meio do corpo dos médiuns, de acordo com seus hábitos e costumes.

A doutrina umbandista afirma que a música (pontos cantados) é capaz de evocar dimensões transcendentes, trazendo-as para perto dos seres humanos. Na Umbanda a música é uma forma de evocação. Ademais, ela tem, também, a habilidade de promover a aproximação entre os indivíduos, com o papel de unificação.

\section{Os rituais}

Iniciam-se os trabalhos da noite com os seguintes rituais:

( 1 ) Oração;

(2) Cantos específicos de cada entidade para a abertura dos trabalhos;

(3) Defumação acompanhada por pontos cantados;

(4) Pontos cantados para chamar as entidades que são específicas daquela noite;

(5) Apresentação das entidades com seus pontos cantados e ritos específicos de cada entidade;

(6) Atendimento aos frequentadores (consultas e passes).

\section{Casa de Caridade Mãe Maria: o espaço e os rituais de trabalho}

A Casa de Caridade Mãe Maria funciona em um salão que foi construído para esta finalidade: ser um Centro de Umbanda. $O$ Centro conta com a presença dos trabalhadores da Casa e com os frequentadores que procuram por atendimentos espirituais - chamados de consulentes/assistência. $O$ portão fica aberto até as 19h30, horário 
que dá início aos trabalhos. $\bigcirc$ portão é aberto às 21 h para os consulentes que já foram atendidos irem embora, porém, o trabalho continua até todos da assistência serem atendidos (por volta de 22h30 é concluído o trabalho todo).

A parte de fora do salão (como uma varanda) há plantas, destacando-se as roseiras brancas e as espadas de São Jorge. Há, também, velas: de um lado há as velas para as almas, e do outro lado, para os exus. $\bigcirc$ lado de fora também consta com banheiros feminino e masculino.

Ao adentrar no salão, encontram-se bancos e cadeiras destinados para a assistência e um espaço para os trabalhadores da Casa. Esta é a caracterização de um espaço intermediário, na qual separa a assistência (os consulentes) dos trabalhadores da Casa. Este espaço é separado por uma pequena mureta. Os consulentes acompanham os trabalhos sentados nos bancos, e, após o início do trabalho (com oração, defumação e pontos cantados) são atendidos um por vez em ordem de chegada.

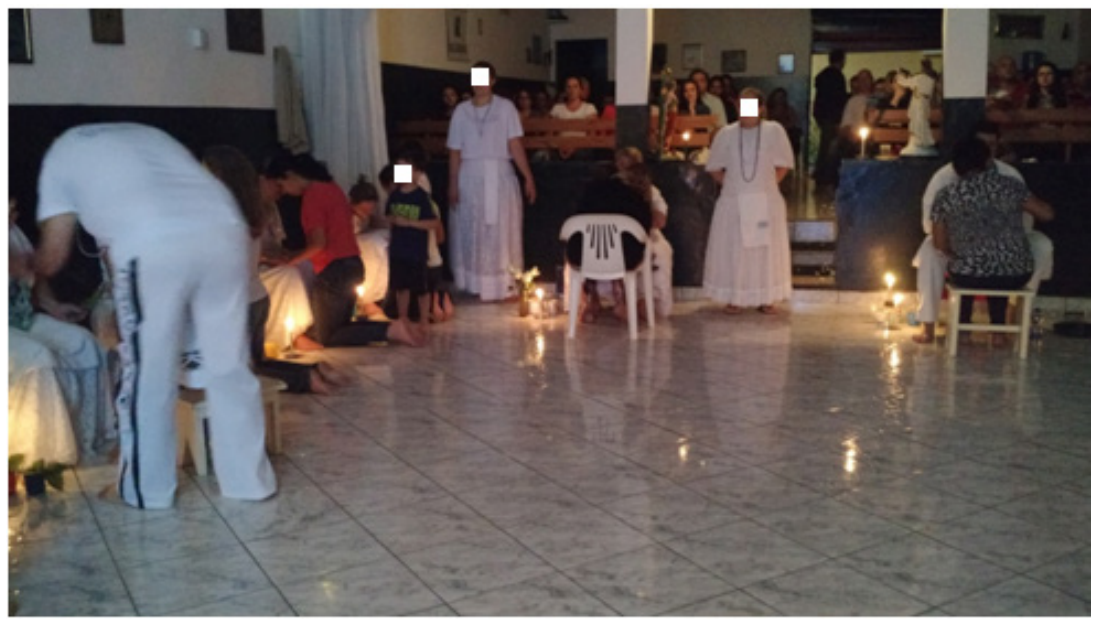

Figura 1: sessão de atendimento. Atrás das cambones (vestidas de branco e posicionadas em pé) vê-se a mureta que separa os ambientes. Fonte: da autora 
Os trabalhadores da Casa, médiuns de psicofonia e cambones, chegam e passam por um corredor ao lado do salão que está localizado a assistência. Há uma entrada na lateral para acessarem - espaço destinado a eles (não é preciso passar pela assistência para adentrarem ao espaço). No local em que os trabalhadores estão, há um altar com as imagens dos santos, entidades e orixás. No centro do altar há uma cachoeira construída com pedras e água corrente, com lâmpadas azuis claras na lateral. Há, também, dois atabaques instrumentos musicais, e estão situados do lado esquerdo do altar.

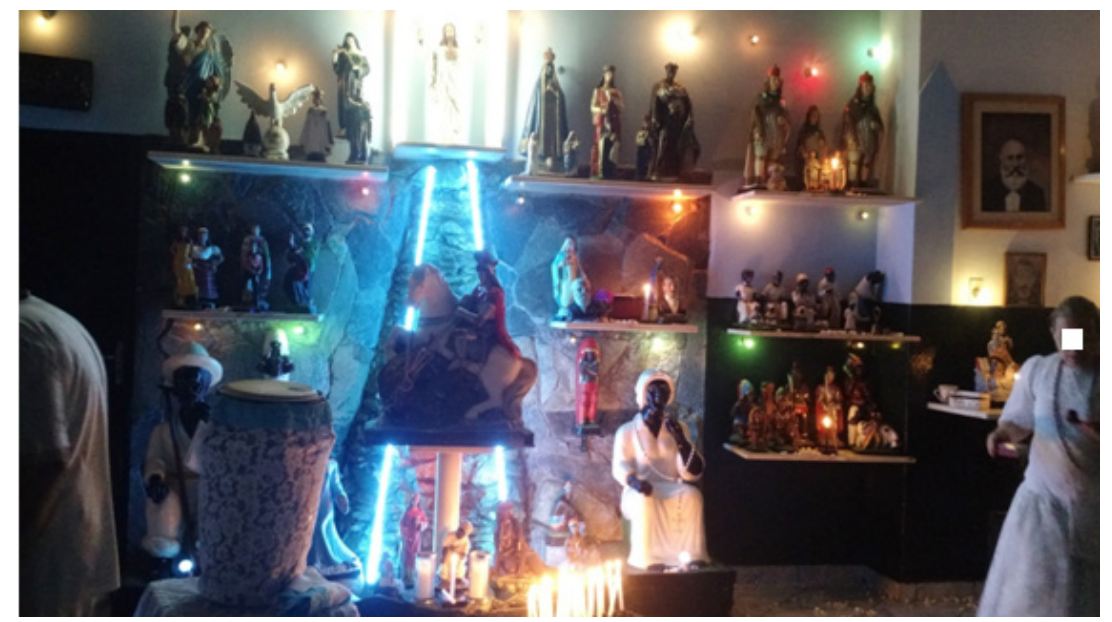

Figura 2: altar com as imagens de santos e orixás, e um atabaque à frente. Fonte: da autora

No começo do ritual há uma cortina de renda branca que veda a visão entre os dois espaços (da assistência e dos trabalhadores da Casa), porém, ela é fechada apenas no início, após, ela é aberta. Para começar a gira são feitas orações e dedicações (pelos trabalhadores que se ausentaram no dia, pelas pessoas necessitadas, por quem pediu/ deixou o nome para oração, pelos hospitais e lugares que precisam de um atendimento espiritual, a fim de amenizar o sofrimento e proporcionar a cura; além de agradecimentos). Após esse rito são cantadas músicas próprias com o acompanhamento dos atabaques (dois) para a entidade dedicada daquele dia. Esse processo (de oração e canto) tem a duração de 30 minutos. No decorrer destes cantos, há saudações para os exus (entidades da esquerda). Neste momento, todos ficam 
de costas para o altar (médiuns e assistência) e cantam a seguinte canção:

"Tava" dormindo na beira do bar

"Tava" dormindo na beira do bar

Quando a Alma me chamou prá trabalhar

Quando a Alma me chamou prá trabalhar

Acorda, Tranca Rua, vai vigiar

Acorda, Tranca Rua, vai vigiar

inimigo está invadindo a porteira do curral

inimigo está invadindo a porteira do curral

Ponha a mãos nas tuas armas, vá guerrear

Ponha a mãos nas tuas armas, vá guerrear

Ponha o inimigo prá fora para nunca mais voltar!

Ponha o inimigo prá fora para nunca mais voltar!

Lá na porteira eu deixei meu sentinela, auê

Lá na porteira eu deixei meu sentinela, auê

Eu deixei seu Tranca Rua tomando conta da cancela

Eu deixei seu Tranca Rua tomando conta da cancela

Esta canção é direcionada aos Tranca Rua, uma linha de exu, com a intenção de pedir auxilio e proteção. É um canto presente em todos os rituais, independente dos guias que estarão presentes. Sobre essa indispensabilidade do canto aos exus, Prandi (2001) constata: "nada se faz sem ele [o exu], nenhuma mudança, nem mesmo uma repetição. Sua presença está consignada até mesmo no primeiro ato da Criação: 
sem Exu, nada é possivel. $\bigcirc$ poder de Exu, portanto, é incomensurável" (PRANDI, 200 I, p. 50).

Após essa "reafirmação aos laços de lealdade" aos exus (PRANDI, 2001 , p. 50), os membros da CCMM voltam a entoar as canções para a entidade do dia. Há o momento da defumação, na qual cantam a seguinte canção (também cantada em todos rituais):

Olha o vento que balança a folha guiné,

Olha o vento que balança a folha

Olha o vento que balança a folha guiné,

Olha o vento que balança a folha

É, é, é, pai guiné, é o vento que balança a folha

É, é, é, pai guiné, é o vento que balança a folha

Guiné é uma planta medicinal, e apresenta um valor simbólico e material nos rituais de terreiros. Carvalho et al. (2015) afirmam: "o uso de espécies vegetais conecta saberes e tradições e mantém acesa a valorização da natureza, manifestada no caráter farmacobotânico de suas receitas, no registro empírico e individual das experiências" (CARVALHO et al., 2015, p. 2). Vemos, então, a importância de pontos cantados serem cultuados como uma maneira do que é considerado tradição nesta religião.

No processo do canto, há os pontos para cada entidade, porém, essas duas canções que foram expostas seguem no ritual de todas as entidades.

Todos os pontos cantados no CCMM seguem o acompanhamento no ataque com a seguinte rítmica: 


\section{Candômbe}

CANDOMBE

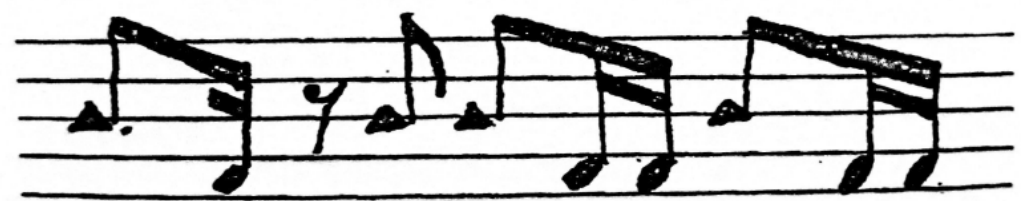

$s$

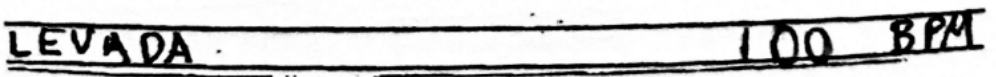

Figura 3: levada rítmica dos pontos tocada no atabaque. Fonte: Percussão corporal para educadores musicais (KUHLMANN, 2012)

Há a diferenciação do som agudo (nota na terceira linha) e do som grave (nota no primeiro espaço) nos atabaques (dois atabaques tocados por dois membros do Centro, um atabaque para cada um). De acordo com Kuhlmann (2012) essa levada rítmica, nomeada de candômbe, é, normalmente, usada nos terreiros de Umbanda.

Os médiuns de psicofonia incorporam, ao final dos pontos cantados, e se preparam para receber a assistência. Pode-se dizer que este momento é chamado de "hora da chamada dos orixás". Quando autorizado, há uma pessoa que é responsável por chamar a assistência, um por um, na ordem em que chegaram, e, então, ocorre o passe e a consulta (os primeiros a serem atendidos são as crianças, após, mantém a chamada pela ordem de chegada). Quando todos são atendidos há a desincorporação (momento em que os espíritos deixam o momento com os médiuns) e há o fechamento da gira, com canto e ao som dos atabaques.

O espaço da Mãe Maria, a Madrinha do Centro, é destinado e caracterizado para receber o espírito que ela recebia quando estava viva. $\bigcirc$ caráter é de acordo com a entidade dedicada na noite, como preto velho, caboclo, entre outros. Mantém-se o espaço como se ela estivesse presente: 


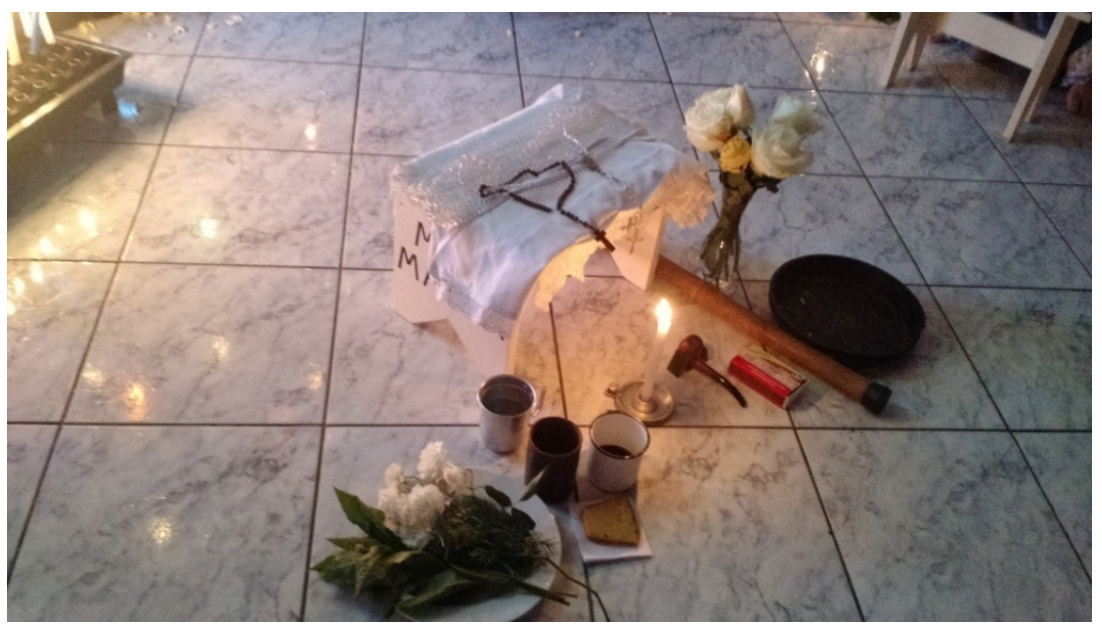

Figura 4: espaço destinado à Madrinha do Centro, que receberia o espírito de preto velho. Fonte: da autora

São, aproximadamente, 30 trabalhadores da Casa, e atendem mais de 150 pessoas por encontro.

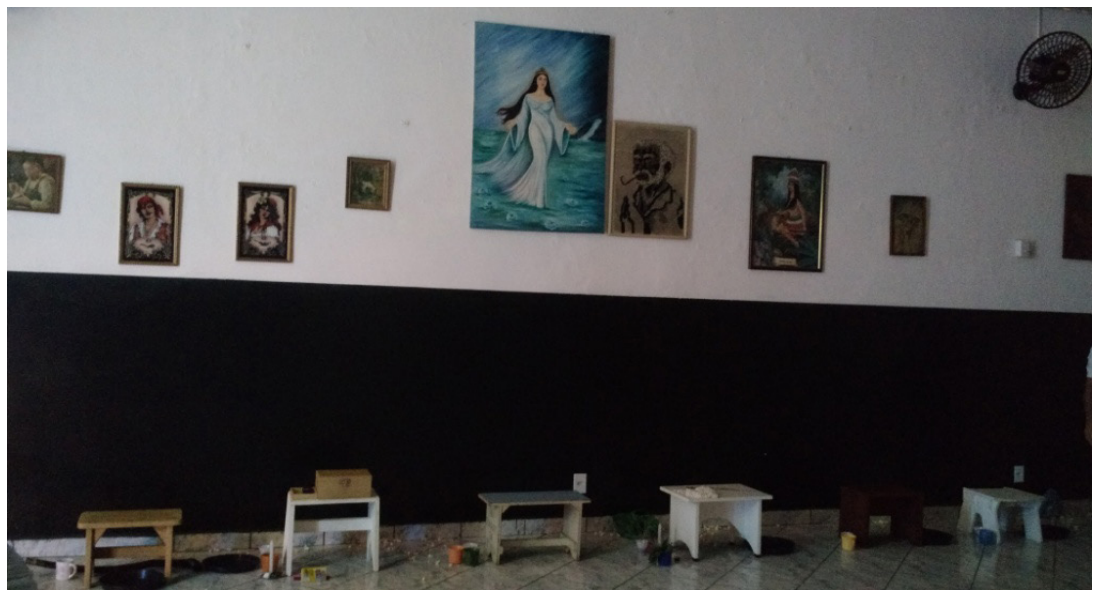

Figura 5: espaço em que os médiuns de psicofonia incorporam e recebem a assistência. Fonte: da autora 


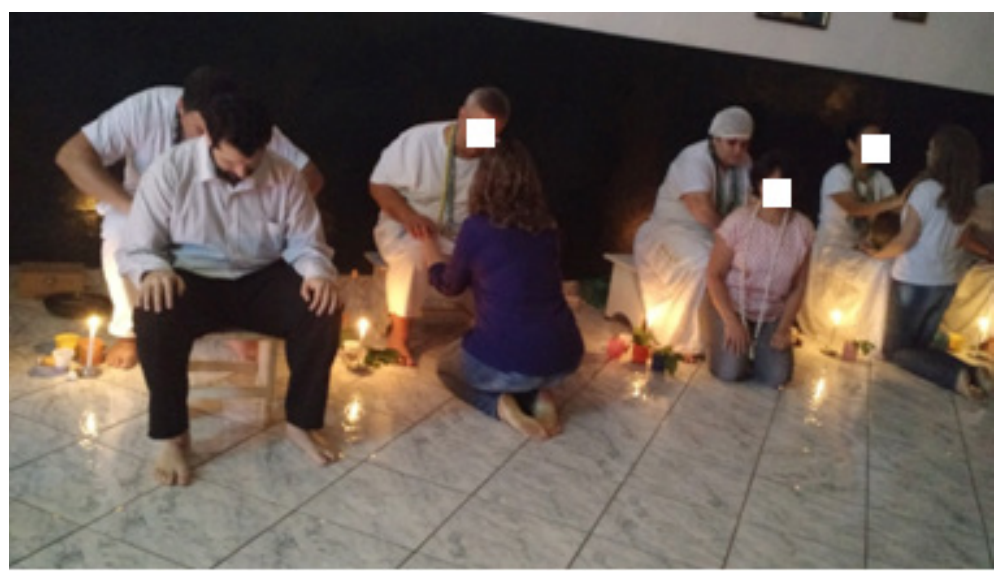

Figura 6: preto velho atendendo a assistência. Fonte: da autora

\section{Trabalho realizado na praia}

Para concluir os trabalhos do ano, o Centro de Umbanda Casa de Caridade Mãe Maria faz um descarrego na Praia Crande, litoral do estado de São Paulo. Esse trabalho é realizado no primeiro fim de semana de dezembro em dedicação à lemanjá. Todos os trabalhadores da Casa e algumas pessoas da assistência que tenham interesse em ir, vão. Há o descarrego na praia no período da tarde e, no período da noite, há o trabalho, como o que acontece no Centro. Este também é realizado na praia, e há a passagem das entidades: preto velho, caboclo, baiano e crianças.

No descarrego é feito uma oração e, após, e alguns médiuns passam o Amaci em todos que estão presentes.

Amaci é um ritual umbandista, onde anualmente os médiuns iniciantes e os mais antigos da corrente devem passar por ele. Este ritual tem a finalidade de preparar o médium para receber as energias vibrantes do terreiro, além de oferecer ao filho de fé a limpeza de seu campo 
áurico, bem como confirmar as entidades trabalhadoras da coroa daquele médium (SOLA, 20 14, n.p.).

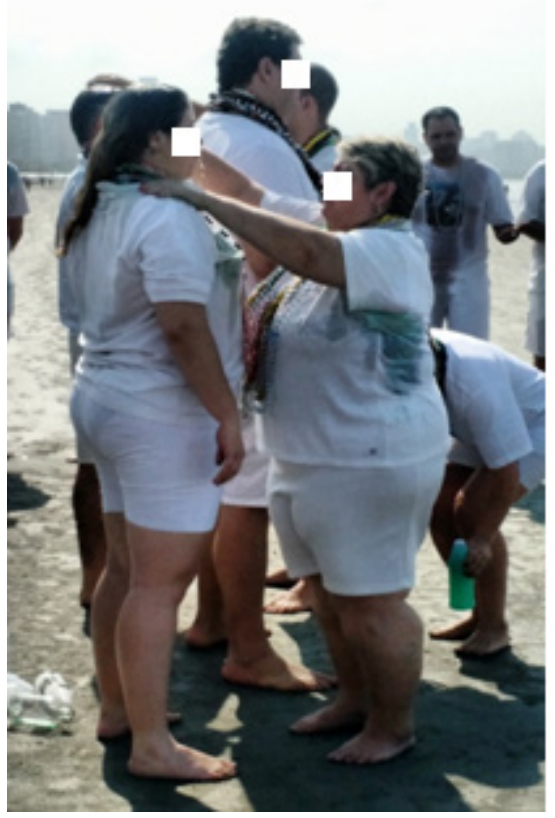

Figura 7: banho de Amaci. Fonte: da autora

Depois de todos tomarem o banho de Amaci, há cinco integrantes do Centro que vão ao mar para fazerem a abertura do descarrego: 


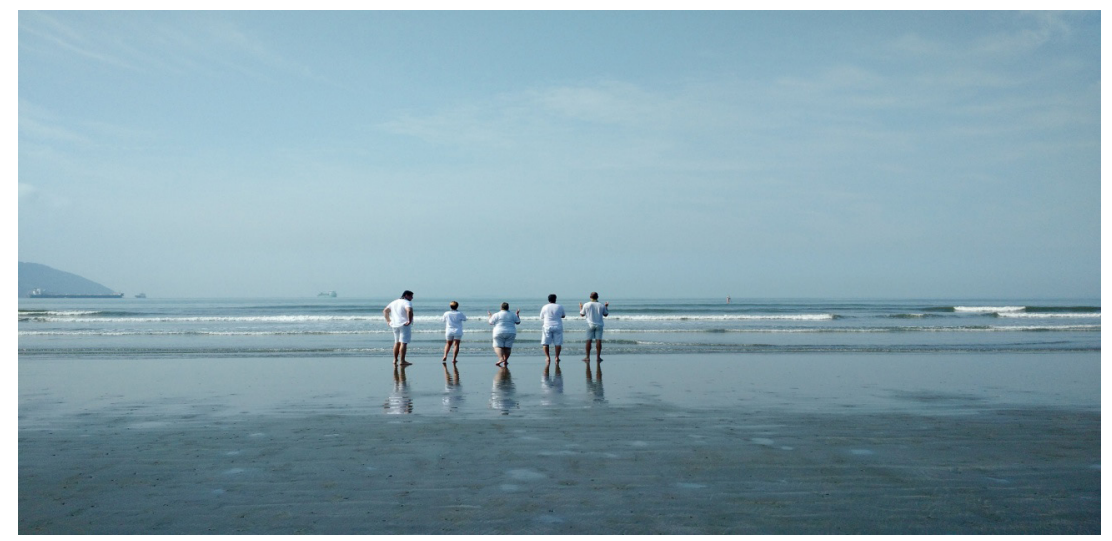

Figura 8: médiuns abrindo o trabalho de descarrego. Fonte: da autora

Após a abertura são convidados para entrarem no mar, por vez: os médiuns de psicofonia, os cambones e, por fim, a assistência.

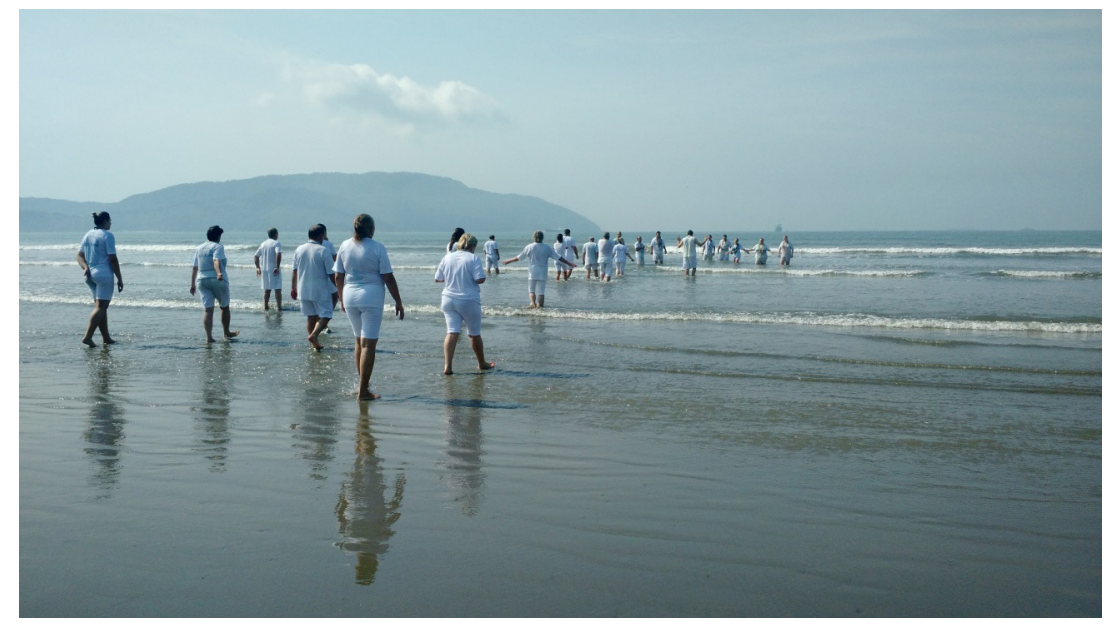

Figura 9: médiuns de psicofonia, cambones e assistência entrando ao mar. Fonte: da autora

Foram feitas saudações à lemanjá, agradecimentos, orações, e canções. Com a perda da Madrinha do Centro (estas coletas foram realizadas em 2016), foi feito, também, um momento dedicado a ela. Médiuns de vidência viram a Madrinha presente no trabalho.

Após essas saudações foi iniciado o banho de mar, na qual todos passaram embaixo de sete ondas. Esta passagem contou com o 
acompanhamento dos cinco médiuns que deram o início aos trabalhos no mar. Eles passavam as ondas junto aos que estavam presentes e, neste momento, era feito agradecimentos, pedidos e o descarrego de tudo o que foi negativo. Foi um momento destinado a absorver às boas energias vindas de lemanjá.

No período da noite, o ambiente foi preparado para ser realizado o trabalho como de costume, porém, à beira mar. Para isso montou uma tenda/barraca e, dentro, havia o altar e toda a preparação que acontece no Centro. $\bigcirc$ trabalho seguiu o mesmo ritual do Centro, e os médiuns de psicofonia deram passagem aos pretos velhos, caboclos, baianos e crianças. Ao final do trabalho, foi enviado um barquinho azul com flores, cartas, perfumes, entre outros materiais, como forma de agradecimento à lemanjá. Cada um que estava presente pegou botões de rosas e dedicou à lemanjá, jogando-as ao mar.

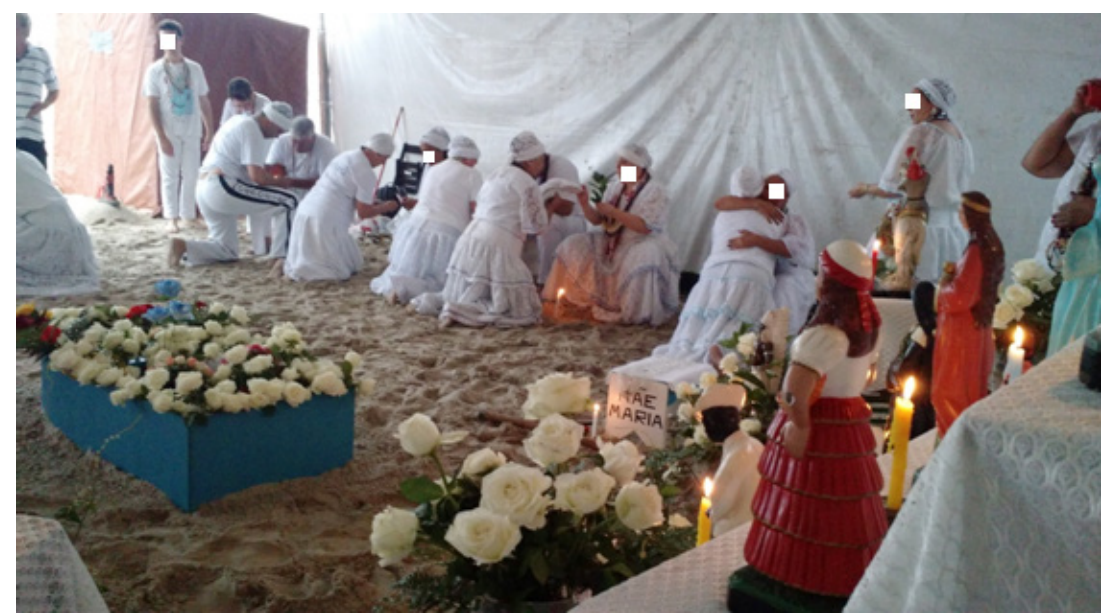

Figura 10: atendimento na Praia. Fonte: da autora

É válido ressaltar que esse dia foi ofertado a todos os Centros de Umbanda e de Candomblé (ou aos que seguem essa linhagem espírita) que quisessem participar deste evento, fazerem os trabalhos na praia. Viam-se várias tendas com vários estilos de trabalho, uma ao lado da outra.

Acredita-se que os trabalhos realizados na praia têm a intenção de buscar elementos da natureza para renovar e equilibrar as energias do corpo, além de saudar e firmar os orixás. 


\section{Pequena exposição de fotos}

Preto velho:

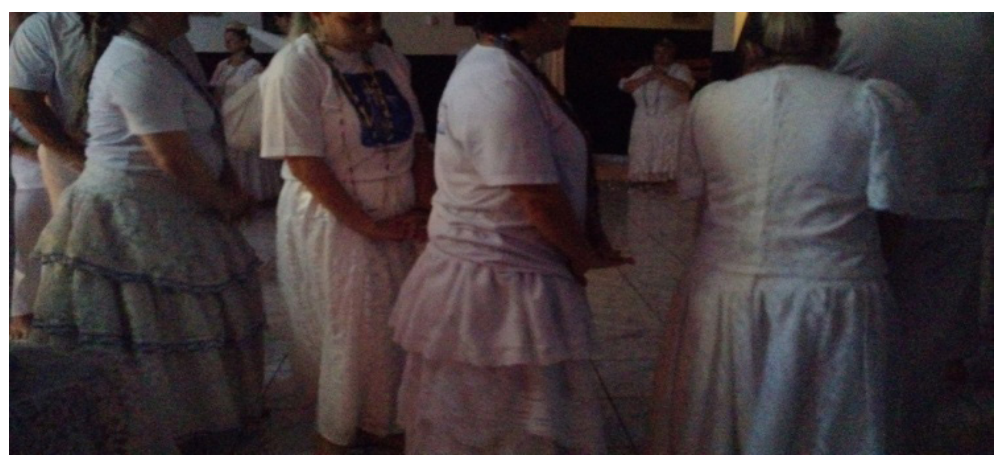

Figura 1 1: roda fazendo a gira aos pretos velhos. Fonte: da autora

Caboclo:
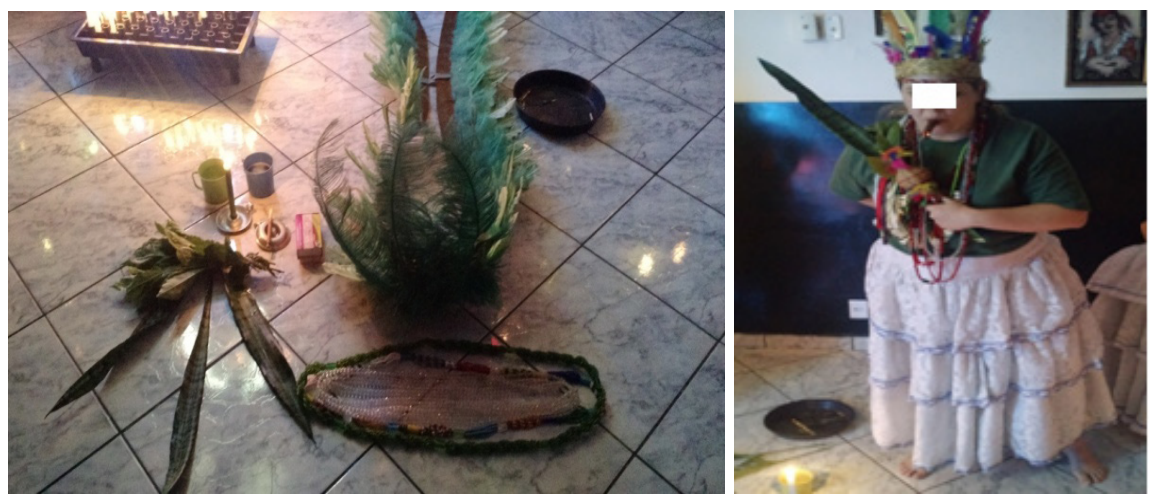

Figura 12: ponto da Madrinha e Cabocla. Fonte: da autora 
Baiano:
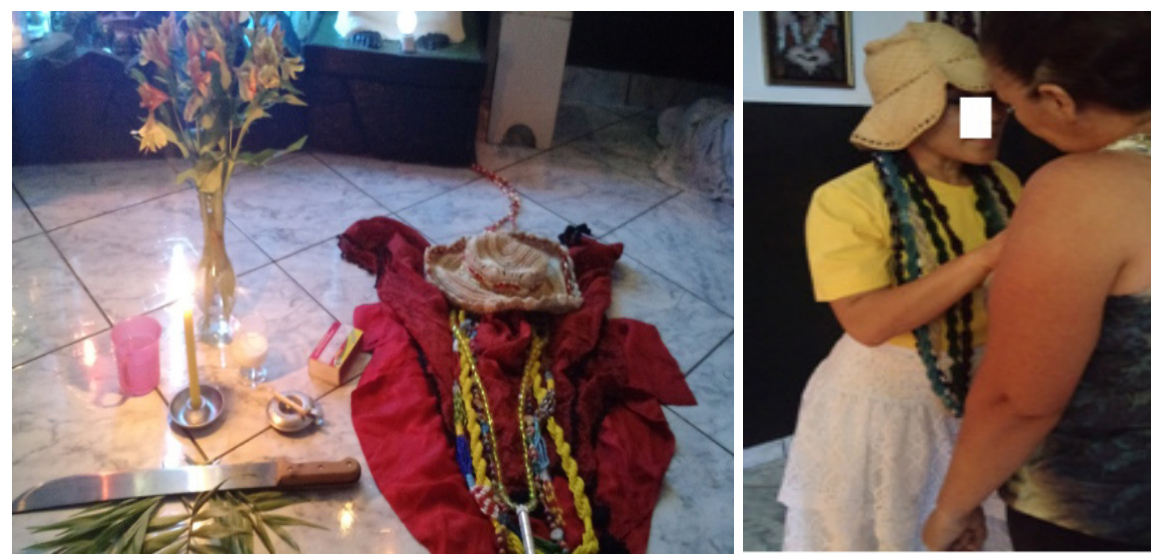

Figura 13: ponto da Madrinha e Baiana atendendo. Fonte: da autora

Cosme e Damião:
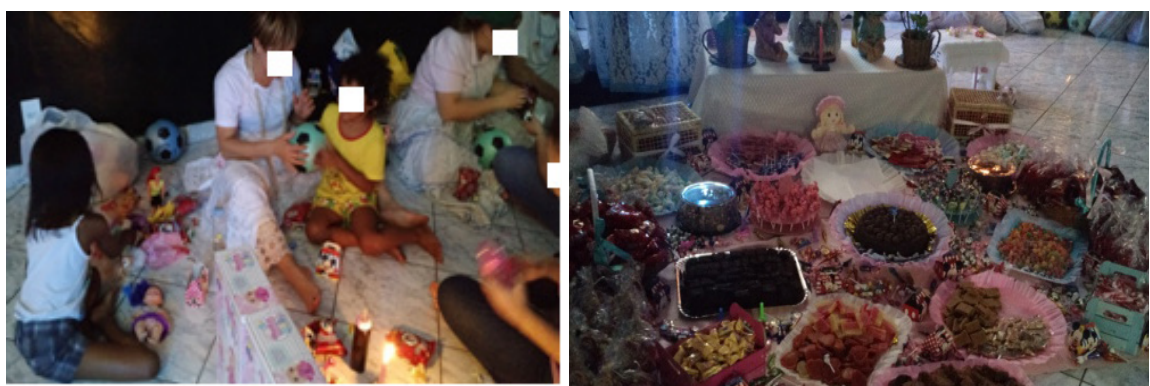

Figura 14: crianças com as crianças e Doces para receber as crianças. Fonte: da autora 
Esquerda:
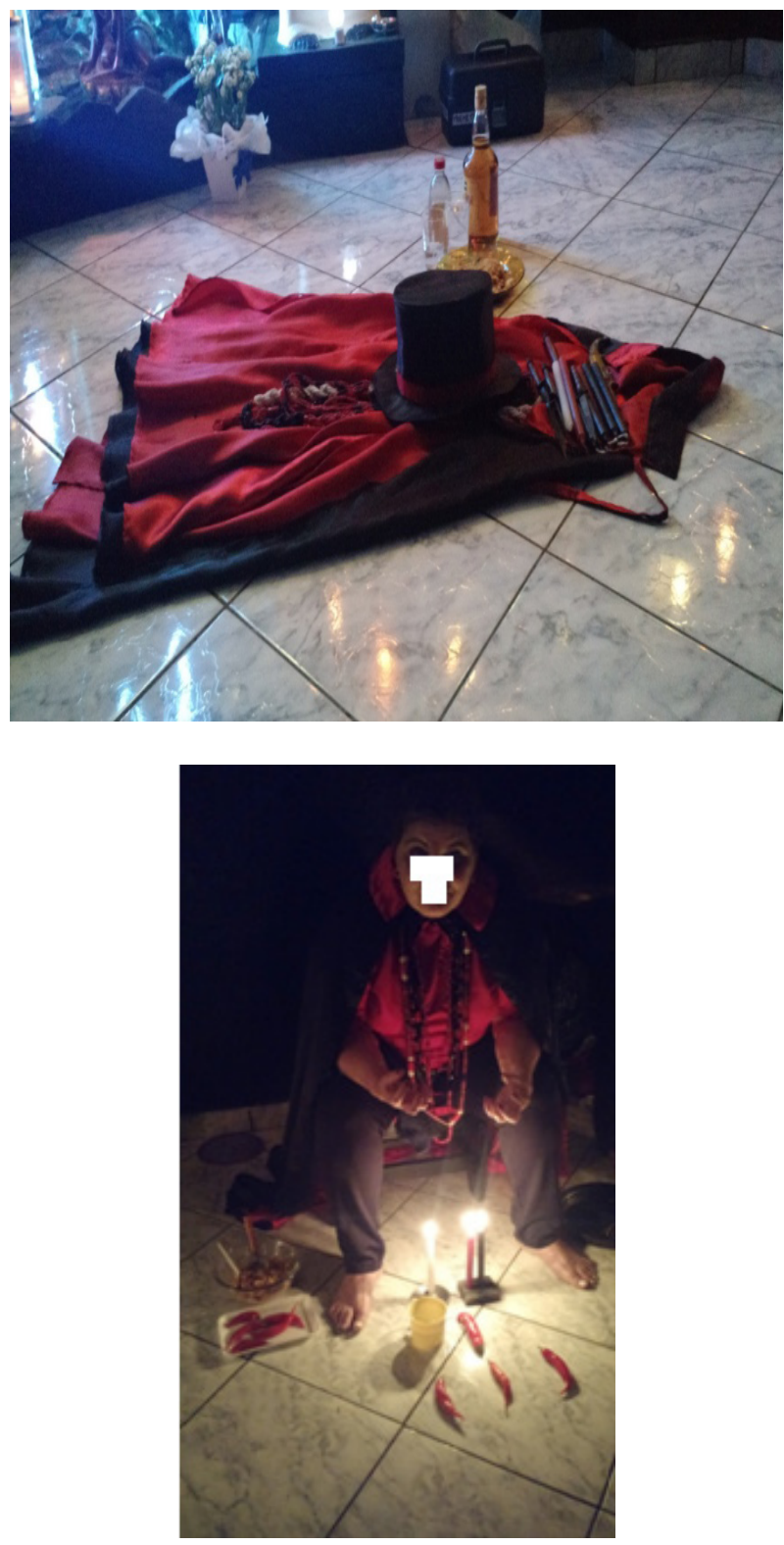

Figura 15: ponto da Madrinha e Médium incorporada de Exu. Fonte: da autora

\section{0}

REV. TULHA, RIBEIRÃO PRETO, v. 4, n. 2, pp. 3 I-53, jul.-dez. 2018 


\section{Considerações finais}

Podemos concluir com este trabalho de etnografia, que a Umbanda é uma religião de caridade e de amor. Busca-se, no Centro de Caridade Mãe Maria, atender e acolher aqueles que buscam por auxílio.

Realizando a pesquisa de campo em um Centro de Umbanda, constatamos que é uma religião atuante, que opera com um repertório próprio. Como Bairrão (2005) afirma, a Umbanda tem a formação de um povo brasileiro (índios, nordestinos, etc.), e isso se caracteriza em uma herança simbólica deixada pela ancestralidade. Ademais, "a Umbanda, com suas entidades espirituais, mostra-se plástica o suficiente para, além de 'acomodar' experiências de vida, ressignificá-las, catalisando construções e transformações de identidades" (ROTTA, 2010, p. 135).

Acrescentando, a música tem suas resalvas no contexto cultural, tornando fundamental na realização dos cultos Umbandistas. Lunelli (2015) afirma: "a soma da música, da dança e do texto é o estímulo do transe, que de fato é o comportamento esperado durante as cerimônias" (LUNELLI, 2015, p. 6). A sua prática, além de ser parte integrante do contexto cultural e facilitar nas manifestações dos orixás, auxilia nos ritos, harmonizando o ambiente e fluindo as emoções.

Por fim, consideramos que trabalho realizado pela Casa de Caridade Mãe Maria oferece, por meio dos ancestrais, subsídios para a formação de uma base sólida aos consulentes. "É possivel libertaremse posições subjetivas (...) e escolher, livremente, 'caminhos' possíveis, de certa forma ditados por essa herança" (ROTTA, 2010, p. 135). Por meio dessa base sólida que oferecem aos consulentes, os ancestrais dão "estabilidade para caminhar, amadurecer e tocar a vida adiante" (ROTTA, 2010, p. 135).

\section{Referências}

BAIRRÃO, José Francisco Miguel Henriques. "A escuta participante como procedimento de pesquisa do sagrado enunciante". Estudos de psicologia. Natal, v. 10, n.3, p.44 1-446, 2005. 
BORCES, Mackely Ribeiro; CHADA, Sonia. "Candomblé e umbanda: o compartilhamento de práticas e repertórios musicais pelas entidades caboclas". In: IV ENABET - Encontro Nacional da Associação Brasileira de Etnomusicologia, 2008. Anais... Maceió: 2008, p.435-444.

CARNEIRO, Edson. Religiões Negras: Notas de etnografia religiosa. 3 a ed. Rio de Janeiro: Civilização Brasileira, 1991.

CARVALHO, Patricia Aparecida; BARROS, Vanessa Maria de Souza; ZONTA, Pauline de Lima Zonta; SOUZA, Helton Nonato. Manutenção da tradição e do conhecimento sobre plantas medicinais em terreiros de Umbanda e Candomblé na Zona da Mata de Minas Gerais. In: IX Congresso Brasileiro de Agroecologia, 2015. Anais... S.l.: 2015, p. 1-9.

FERREIRA, Aurélio Buarque de Holanda. Novo Dicionário da Língua Portuguesa. $3^{a}$ Edição. Curitiba: Editora Positivo, 2004.

KUHLMANN, Yurê Abondanza. Percussão corporal para educadores musicais. S.l.: impresso por Yurê Abondanza Kuhlmann, 2012.

PRANDI, Reginaldo. "Exu, de mensageiro a diabo: sincretismo católico e demonização do orixá Exu”. Revista USP. São Paulo, n. 50, 2001. p. 46-63,

v. 18 ก. 52,2004 .

"O Brasil com axé". Estudos avançados. São Paulo,

Segredos guardados: orixás na alma brasileira. São Paulo: companhia das letras, 2005.

LUNELLI, Diego Conto. "Processo de ensino/aprendizagem em casa de religião: um estudo de caso". In: XXII Congresso Nacional da Associação Brasileira de Educação Musical, 2015. Anais... Natal: 2015, p. $1-12$.

PINTO, Tiago de Oliveira. "Som e música: questões de uma antropologia sonora”. In: Revista de antropologia, 2001. São Paulo: 2001, p. $221-286$.

QUEIROZ, Gregório José Pereira. Uma visão psicossocial do papel da música na umbanda e na reorganização da id/entidades. $2017.444 \mathrm{f}$. Dissertação (Mestrado em Psicologia Social e do Trabalho), Instituto de psicologia - Universidade de São Paulo, São Paulo, 2017. 
ROTTA, Raquel Redondo. Espíritos da mata: sentido e alcance psicológico do uso ritual de caboclos na Umbanda. 2010.145f. Dissertação (Mestrado em Psicologia), Departamento de Psicologia e Educação, Universidade de São . Ribeirão Preto, 2010.

SOLA, Victor Henrique Stivanin. "Templo de umbanda caboclo Ubirajara". 2014. Disponivel em: <http://www.tucabocloubirajara.com/ ritual-amaci/> Acesso: 14/09/2016.

\section{Sobre os autores}

Bianca Viana Monteiro da Silva é mestranda do Programa de Pós-Graduação em Música, linha de pesquisa Música e educação: processos de criação, ensino e aprendizagem, sob orientação do Prof. Dr. Marcos Câmara de Castro, pela Escola de Comunicação e Artes da Universidade de São Paulo (ECA-USP). É graduada em Educação Artística com habilitação em Música pelo Departamento de Música da Faculdade de Filosofia, Ciências e Letras de Ribeirão Preto da USP (FFCLRP-USP), e foi conferida com menção honrosa por ter se destacado com a mais alta média de notas no curso.

Marcos Câmara de Castro é escritor e Professor Associado do Departamento de Música da Faculdade de Filosofia, Ciências e Letras da USP de Ribeirão Preto (SP), responsável pelas disciplinas: Canto Coral, Educação Musical e Etnomusicologia. Tem graduação (1983), mestrado (2001) e doutorado (2007) pela ECA/USP, aperfeiçoamento no CNSM-Paris, com bolsa CNPa (1988-1990) e pós-doutorado na Universidade de Lorena, Nancy (França) com bolsa BPE/FAPESP. É líder do grupo de pesquisa (CNPq) EsTraMuSE: estudos transdisciplinares em música, sociedade, educação, e desde 2016 é pesquisador associado no projeto temático FAPESP 2016/053 18-7, O Musicar Local: novas trilhas para a etnomusicologia. É editor-gerente da Revista da Tulha.

Recebido em 08/07/2018

Aprovado em 18/12/2018 